\title{
Patient-centered decision making in amyotrophic lateral sclerosis: where are we?
}

\author{
Anne Hogden*,1 \& Ashley Crook ${ }^{2}$ \\ ${ }^{1}$ Australian Institute of Health Innovation, Faculty of Medicine \& Health Sciences, Macquarie University, Sydney, New South Wales, \\ Australia \\ ${ }^{2}$ Department of Clinical Medicine, Faculty of Medicine \& Health Sciences, Macquarie University, Sydney, New South Wales, \\ Australia \\ * Author for correspondence: Tel.: +61 29850 2417; Fax: +61 29850 2499; anne.hogden@mq.edu.au
}

\section{Practice points}

- Amyotrophic lateral sclerosis patients are supported by models of patient-centered decision making delivered through specialized multidisciplinary clinics.

- Advances in research have led to changes in service delivery, with new members added to the multidisciplinary team.

- Developments in genetics research have increased the complexity of patients' choices for genetic testing.

- User-designed decision support tools could improve communication between patients' families and clinicians, to negotiate this complex and ever-changing care.

Developments in amyotrophic lateral sclerosis research and care delivery have created new arenas, and new dilemmas, for patients' decision making. This review explores three aspects of amyotrophic lateral sclerosis patient-centered care and decision making: patient-centered service delivery through the expanding multidisciplinary team; decision making for genetic testing and the implications of undergoing testing; and development of user-designed decision support tools to help patients and families make decisions as their choices become more complex. Until a cure is found, well-timed and effective decision making will rely on patient and family preferences to guide them through an increasingly complicated disease landscape.

First draft submitted: 10 July 2017; Accepted for publication: 24 August 2017; Published online:

22 November 2017

Keywords: decision-support tools $\bullet$ genetic counseling $\bullet$ genetics $\bullet$ multidisciplinary care

Amyotrophic lateral sclerosis (ALS) is a disease in search of a cure, or at least a highly effective treatment that will alleviate symptoms and slow disease progression. Until this can be achieved, people living with ALS, and their families, rely on healthcare services to help them manage their symptoms and maximize their quality of life as their needs increase. Best practice for people with ALS adopts a multidisciplinary approach of specialized care [1] that draws on patient- (or person-) centered principles and practices for cohesive and collaborative care [2].

Patient-centered care, and the decision making that underpins it, have been defined, conceptualized and modeled many times [3-7]. In short, four principles [5] apply: affording people dignity, respect and compassion; offering coordinated care; offering personalized care; and enabling people to develop their unique range of capabilities to participate in their own care. Shared decision making, where patients and health professionals collaborate to arrive at a care decision, is considered best practice for patient-centered healthcare delivery [8]. Although preferences for sharing decision making vary with age, cultural background and disease setting [9-11], a majority of patients prefer to make their decisions using this approach [9]. Decision making for ALS care is often more complicated than for other degenerative conditions, as continual change in the patient's condition and circumstances mean that decision making is ongoing throughout the, frequently brief, course of the disease. Time frames for choosing and implementing a treatment may be short; and the number of health professionals to consult may be extensive; with multiple decisions under consideration at one time. 
Table 1. Multidisciplinary team support for patient decision making.

\begin{tabular}{|c|c|c|}
\hline Issue & Treatment options & Healthcare and support professionals involved \\
\hline Familial ALS & Genetic testing & Neurologist, genetic counselor \\
\hline Disease progression & Riluzole & Neurologist/rehabilitation physician \\
\hline Breathing difficulty & Assisted ventilation & $\begin{array}{l}\text { - Respiratory physician } \\
\text { - Respiratory therapist } \\
\text { - Nursing }\end{array}$ \\
\hline \multirow[t]{2}{*}{ Eating and drinking difficulties } & Gastrostomy & $\begin{array}{l}\text { - Gastroenterologist } \\
\text { - Dietitian } \\
\text { - Speech pathologist } \\
\text { - Nursing }\end{array}$ \\
\hline & Safe swallowing strategies & Speech pathologist \\
\hline \multirow[t]{3}{*}{ Saliva management } & Medication & Neurologist/general practitioner/palliative care team \\
\hline & Botox & Neurologist \\
\hline & Natural remedies and swallowing behavior & Speech pathologist \\
\hline Mobility & Mobility equipment & $\begin{array}{l}\text { - Physiotherapist } \\
\text { - Occupational therapist } \\
\text { - ALS association }\end{array}$ \\
\hline Self-care & Assistive equipment and strategies & $\begin{array}{l}\text { - Occupational therapist } \\
\text { - Nursing } \\
\text { - ALS association }\end{array}$ \\
\hline Assistance with personal care & Purchased care services & $\begin{array}{l}\text { - Social worker } \\
\text { - Occupational therapist }\end{array}$ \\
\hline Communication & Alternative communication strategies and devices & $\begin{array}{l}\text { - Speech pathologist } \\
\text { - Occupational therapist } \\
\text { - ALS association }\end{array}$ \\
\hline Grief and loss & Counseling and support for patient and family & $\begin{array}{l}\text { - Social worker } \\
\text { - Psychologist } \\
\text { - ALS association } \\
\text { - Palliative care team }\end{array}$ \\
\hline Family carer support & Counseling and support for patient and family & $\begin{array}{l}\text { - Social worker } \\
\text { - ALS association } \\
\text { - Palliative care team }\end{array}$ \\
\hline
\end{tabular}

How people with ALS patients respond to these complexities varies [12]. A small proportion of patients choose to make decisions independently of professional advice, or independently of family considerations [13]. Some prefer to share their decision making only with family members. Others rely on health professionals or family members to make decisions for them [13]. Studies reveal that, in many degenerative conditions, patient preferences for involvement of others can vary over time [14], or with each decision, but it is unknown if this is the same for people with ALS.

This review explores what is known about ALS patient decision making; that is, how patient-centered principles, and the clinical processes and activities by which they are enacted [5], are implemented within ALS service delivery. Three aspects of ALS care are discussed, to reveal how research developments have translated into patient care, and influenced decision making. These processes and activities are: the multidisciplinary model of service delivery, decision making for genetic testing and user-designed decision support tools for patients.

\section{Patient-centered service delivery}

Multidisciplinary clinic (MDC) teams specializing in ALS provide best possible care for, and improve survival of, people living with ALS [15-17]. The teams are comprised of a range of medical, nursing and allied health practitioners, taking an integrated approach to address patients' symptom management, psychosocial and quality of life needs [18-20] (Table 1).

MDC care for ALS is underpinned by evidence from healthcare research [13,21], and supported by clinical standards and guidelines [1,22-25] that reinforce the importance of meeting patients at their current and projected 
points of need, rather than merely addressing a set of deteriorating symptoms. Not all patients are able to attend an MDC; but, despite numerous barriers to attendance [26], the proportion of patients who have been able to access specialized multidisciplinary services is high internationally [20].

Since their establishment in the late 1990s [27], MDCs have evolved to accommodate new treatments and practices that have emerged from research findings. Remote services using telehealth are emerging [28]. Team membership has expanded to provide more comprehensive care as understanding of the disease improves. Of note, the association between frontotemporal dementia (FTD) and ALS [29], and development of mild cognitive and behavioral change in many ALS patients [30], has seen neuropsychologists added to the MDC team. Neuropsychologists provide assessment and advice to patients and family members, and guidance to the MDC team, particularly where concerns are held about the patient's capacity for making informed decisions. Similarly, advances in ALS gene identification have led to genetic counselors working more closely with ALS patients and family members [31]. Their role is discussed in greater detail below.

Patient-centered care and decision making have long been fundamental to models of MDC care [15,19,32-33], but our notion of who forms this 'patient center' has changed over time. While family members providing care are included in many models of ALS MDC care [18-19,25], it is not until recently that the extent and value of that care have been documented. As family caregivers often shoulder the physical, emotional, logistical and financial burden of care, including economic disadvantage through loss of productivity [34,35], many are placed in the role of co-decision maker alongside the patient. For some, the role is of proxy decision maker, if the patient's capacity for decision making becomes impaired by FTD. In these circumstances, patient-centeredness is characterized by negotiation between what the patient wants, and what is considered to be in their best interest. Thus, for many families, patient-centered care includes addressing the needs of the patient's caregiver [36,37], to allow them to continue this support. Addressing carers' needs from within, and in addition to MDC care [36,38], has potential to reduce the strain associated with caregiving [38].

How well MDCs and general health services respond to the growing role and support needs of caregivers is yet to be seen. People with ALS, and their carers, who are unable to access MDCs are faced with the additional challenge of how best to receive care from services where ALS is not a high-priority caseload, or where practitioners have little experience of the disease. Tools such as the Red Flags checklist [39] that support the general practitioner (GP) - or family physician - decision making and reduce their uncertainty have potential to improve practitioners' awareness of the needs of ALS patients. Furthermore, service delivery that is guided by patient preferences becomes key to negotiating care when treatment and service options are of limited effect and availability. Care delivered by practitioners working in isolation can be patient centered within each clinical encounter, supported by shared decision making. However, patient-centered care is more difficult to maintain along the chain of service provision between unconnected, internal and external service providers, without an agreed care model to underpin it.

\section{Decision making for genetic testing}

Interest in finding a cure or treatments that reduce symptoms or enable a normal lifespan, and the desire to help future generations, has encouraged patients and their family members to participate in ALS research [40]. 10\% of ALS cases are estimated to be familial, and to date, more than 20 genes have been discovered that are causal or associated with ALS, along with other conditions, such as FTD [41]. Only two-thirds of clearly familial cases have a known causal gene mutation, and therefore further gene discovery is likely [42-44]. Even a small proportion of individuals with apparently sporadic ALS have been identified to carry a causative gene mutation [44,45], and therefore the number of cases thought to be familial may be an underestimate [46].

Over the past 25 years, our growing understanding of inherited ALS has provided more opportunities for patients to undergo diagnostic genetic testing to determine whether they carry a causal mutation in an ALS gene (Figure 1).

Once a causal gene mutation is identified in an individual, there is currently no change to the patient's medical care or management, although drug therapy trials may be targeted to certain gene mutation carriers in future $[47,48]$. Their unaffected relatives can undergo predictive genetic testing to determine whether they have inherited the mutation, and are at risk of developing the disease in future. Genetic testing and counseling practice for ALS genes differs in research and clinic settings, and between countries and clinicians [49]. Genetic counseling is a general requirement for individuals undergoing predictive genetic testing, and is based on shared decision making principles [50]. In this process, the various medical, psychological, social, familial and reproductive factors that influence and impact pretest decision making are raised, with the aim to help individuals make an informed decision about genetic testing, and at the same time minimize adverse outcomes, such as emotional, ethical and 


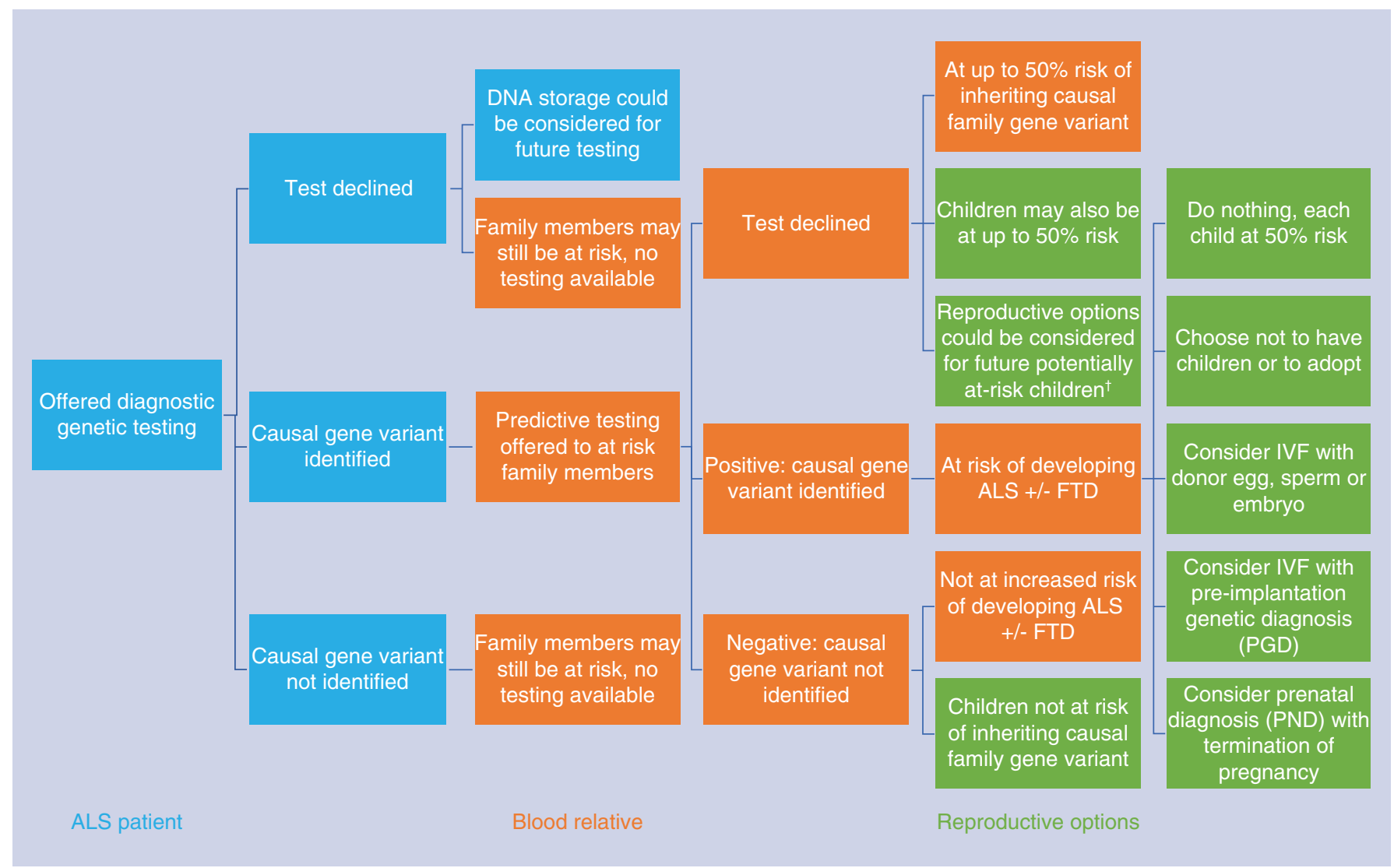

Figure 1. Process of clinical genetic testing for amyotrophic lateral sclerosis genes.

NB: Not all genetic testing options are accessible everywhere.

† Individuals who do not wish to know their mutation status can also consider options to prevent passing on the mutation, such as grandparental exclusion studies via PND or PGD, or nondisclosure through PGD.

FTD: Frontotemporal dementia; PGD: Preimplantation genetic diagnosis; PND: Prenatal diagnosis.

legal implications [23,51-52]. Multiple family members (including carers and blood relatives) may be involved in the shared decision making about genetic testing, given:

- the results of testing may have medical, emotional, social and (potential) insurance implications on not only the patient being tested, but also their family members [51];

- the ALS patient may also have FTD or some cognitive impairment and therefore they may not be cognizant of informed consent, and require another person as proxy decision maker.

Crook et al. (2017) recently reviewed research assessing why individuals choose to have predictive genetic testing for familial ALS and/or FTD genes, to reveal a variety of reasons [53]. These include hope for a $50 \%$ chance of testing negative for the family mutation [54,55]; alleviation of anxiety; and freedom from uncertainty [54,55]. The information individuals gain may help them to alter life priorities, such as family, financial, lifestyle, goal and relationship planning [54,56]; enable time to be psychologically prepared for the future; and be proactive about their health. Still, the uptake of genetic counseling and predictive genetic testing in individuals at risk of inheriting an ALS gene mutation is estimated to be less than $10 \%[56,57]$.

Reasons for declining testing are similarly varied, and sensitive to individual's preferences and values. There are no preventative measures currently available to prevent, delay or effectively slow disease progression to allow a normal lifespan [55]. Moreover, for people who test positive, there are potentially negative consequences for their future employment, insurance, personal and family relationships, privacy, confidentiality and opportunities for their family [55]. Family member's concerns about coping with disclosure of results may result in increased anxiety, depression and stress; feelings of loss of control; feeling flawed; anger and frustration; and worry about developing 
disease [55]. Additionally, some may wish to avoid guilt related to passing on gene, inheriting or even not inheriting the family mutation (a form of 'survivor guilt') [55]. Residual uncertainty relating to if, when and how the condition will manifest will remain. Other reasons to reject testing include: guilt over tampering with nature [55]; an individual believing they already have the gene mutation and thinking continually about the disease [54]; feeling at risk of unresolved grief for a loved one lost to ALS/FTD; and evoking traumatic childhood memories of the disease [54].

Patient and family decisions become even more complex when family planning is considered. Individuals in familial ALS families with known gene mutations also have opportunity to consider reproductive options to prevent passing on the causal gene mutation to their future children. If taken up, these methods can also prevent and reduce the overall incidence of ALS in the next generation.

Studies assessing reproductive decision making in familial ALS have revealed a range of responses to this option [5556,58 . These include: doing nothing differently (retaining a 50\% chance for each pregnancy that the mutation has been passed on); choosing not to have children; prenatal diagnosis; pre-implantation genetic diagnosis (via in vitro fertilization); and conception using donor sperm or egg via in vitro fertilization. Even so, little is understood about how individuals from these families decide whether to have genetic counseling, have genetic testing and undergo reproductive options, and the factors that influence decision making and uptake of these options are largely unknown [54-58].

Evidence-based clinical guidelines to support patient-centered decision making for genetic testing are notable by their absence. Genetic counseling and genetic testing has been excluded from recent ALS management guidelines [22]. Previous guidelines on genetic testing have not kept pace with research developments, with information related to the SOD1 gene only [23] or lacking reference to the reproductive options available to ALS families [31]. As there have been few studies on genetic counseling and genetic testing in familial ALS, most existing guidelines draw on research performed in Huntington's disease genetic testing [23,31,59-61]. While the diseases have some similarities in terms of management and carer involvement, additional issues can arise in predictive testing for familial ALS, as mutations in ALS genes have greater genetic and clinical heterogeneity with variable penetrance, age of onset, phenotype and prognosis [31,42,56,62-63]. Given this variability, it is possible that individuals from ALS families may respond to genetic information differently to individuals from Huntington's disease families [64] and therefore will require a different set of guidelines for genetic counseling and testing. This highlights an opportunity to develop more up to date, current guidelines on genetic testing and counseling for ALS genes to assist patients, families and health professionals to promote patient-centered decision making.

\section{User-designed decision support tools}

In addition to choices for genetic testing, people living with ALS face a range of decisions about their care that can affect their quality of life. As well as evidence-informed practice, there is an increasing demand for information about experimental, complementary, alternative and off-label treatments with unknown or unclear benefits to people with ALS. A range of online resources are available to patients and families to make informed choices about established or emerging treatments. These include ALS support association websites, information sites tapping in to social media, such as ALSUntangled [65] and peer research forums, such as PatientsLikeMe [66]. Nevertheless, the course of ALS, and the response of patients and families to receiving this diagnosis, continues to challenge welltimed and effective decision making [13]. As well as credible sources of information, patients managing deteriorating neurological symptoms need services that provide timely, skilled care in response to patients' dynamic priorities and needs. The uncertainty that accompanies continually changing neurological conditions [67] often renders simple models of decision making inadequate [13].

One way to support ALS patients and families to make choices in a timely way is through the use of patientcentered decision making support tools [68]. Decision support tools help patients to make informed and well-timed choices about treatment, in line with their personal preferences and values [8]. The tools can be used to inform patients about the treatment options available and the associated risks and benefits of the treatment, including the likely health and quality-of-life consequences for them in the short- and long-term. Research on effectiveness indicates that decision support tools can increase patient engagement in healthcare decision making, strengthen communication between patients and health professionals, reduce unnecessary treatment and avoid emergency admissions [69].

Decision support tools designed for ALS, and processes for their use in MDC care, can offer a framework to enhance patient-centered service and quality of care, by guiding care discussions between health professionals, patients and families. Patients are then equipped to make decisions based on a clear understanding of the risks and 
benefits of the available options, and the possible consequences of delaying active treatment, or choosing to do nothing [70]. With limited life-extending options available to ALS patients, treatment and care choices based on patients' personal preferences and values become increasingly salient to how care is negotiated [71]. Decision support tools can also help patients to recognize and clarify their personal preferences, values and attitudes that relate to each decision. This is particularly important in ALS care, where ethically complex and challenging decisions, such as prolonging life through artificial means, are heavily preference sensitive and value based. Moreover, as current ALS treatments will not cure, delay or mitigate the disease process, patients can only consider options that alleviate symptoms, maintain their quality of life, or reduce the risk of a distressing death.

The patient-centered foundation of decision making in ALS is further enhanced by the way decision tools are designed and developed. To ensure usability by patients and families, and feasibility for clinical care, tools that are co-designed by patients, carers, health professionals and researchers can be tailored to ALS patients' specific needs, with potential to optimize patient and carer participation in care planning, and enhance patient's quality of life [72]. Tools can facilitate well-timed decisions by providing patients with a greater sense of autonomy and ownership over planned treatments. The views of health professionals are also important to the tool development process. Their contribution promotes feasibility of the tools for use in clinical settings, with a focus on placing the patient and their carers at the core of decision making. Being able to co-design solutions - whether strategies for symptom management, methods of service delivery, or issues of healthcare policy development - is an effective and rewarding way of improving the lives of people living with ALS, with the potential of longer-term, sustainable positive impact on quality of life for both patient and carer $[71,73]$.

Hogden et al. (2016) applied a process of co-design to the development of ALS decision support tools, using an expert panel of ALS patients, carers, health professionals and researchers, support association representatives and decision tool researchers [68]. This expert panel identified 56 options for symptom management and quality of life that are frequently encountered by ALS patients and their families. The options fell into a range of categories that included medication, procedures, support services, equipment and end-of-life concerns. From these categories, six high-priority topics were selected as suitable for development into a decision support tool. The topics selected for development were: use of gastrostomy to support nutrition and hydration; use of assisted ventilation; decision making for genetic testing; choice of end-of-life care location; choices for communication equipment; and advance care planning.

Once these tools are developed, two further considerations for patient-centered decision support arise: how will patients and families access the tools, and how will the tools be delivered in clinical care? The means of access and delivery are likely to influence the tools' clinical usefulness and sustainability within clinical practice. Decision support tools for a range of conditions are available in paper [67], app [74] and web-based [72] formats. While all have distinct advantages and disadvantages, consideration must be given to what best supports ALS MDC care. Tools developed as websites are likely to offer greatest benefit, by being easily accessible at both the point of care (clinic or home based) and outside of clinical consultations by patients and families. Web-based tools can also be readily updated and maintained as new clinical information becomes available. Thus, they enhance patients' access to reliable health literature by linking to websites that offer evidence-based information such as those of ALS support associations to provide a rich source of best practice information for patients, families and health professionals. Patients and families can access them from home, in advance of consultations and consequently be better prepared for decision making. Web-based tools can also be emailed or printed to provide hard copies for patients and families who prefer to receive paper-based information. Ideally, they can be used in a range of ALS clinical settings, with individual practitioners or within a multidisciplinary team. Web-based tools accessed from mobile devices, such as a tablet, laptop or phone, allow clinicians to discuss decision making wherever convenient to the patient.

\section{Future perspective}

The worldwide incidence of ALS is projected to increase by $69 \%$ by the year 2040 [75]. As research uncovers better understanding of the causes and treatments of ALS, the need for healthcare services to bridge the gaps between research and the services routinely offered to ALS patients and families intensifies. Closer integration of ALS MDCs with ALS research units may be one way to achieve this. Co-location of clinics and research centers, with regional MDCs connected to a research center as satellites, may facilitate translation of bench findings into direct patient care, allow closer connection between patients and those attempting to eliminate their disease and offer support to health professionals and ALS support services. Remote healthcare offered by telehealth may also provide an avenue for services and researchers to connect with patients and families unable to attend MDCs. Linkage between research 
and healthcare services potentially has a two-way benefit of facilitating high-quality patient care, and promoting patient participation in consumer-focused research.

Nevertheless, until a cure or highly effective treatment is found, future research findings will serve to make patients' symptom management and quality of life choices more complex. Treatment options that are targeted to ALS phenotypes or to familial ALS genotypes [47-48,76] will necessitate stronger decision making support for patients and families to understand and consider their options. Patient-centered decision tools and patient-oriented processes for their use in clinical care will become pivotal to providing support and facilitating communication for increasingly complex care.

Increasing availability of ALS patient research samples along with whole-genome sequencing technology is likely to continue to increase our knowledge of the genetic basis of some ALS cases [77]. There is a need for consensus on who should be offered diagnostic genetic testing for ALS genes, and which genes should be tested. Current viewpoints range from clearly familial cases only, to all individuals with ALS and FTD [23,31,49]. Yet importantly, consensus on a definition of familial and sporadic ALS among clinicians is still lacking [49].

As more genes are identified, a process of repeated screening for patients and families is necessitated. Genetic counseling should be offered routinely to all ALS patients [78], ideally through accessing ALS MDCs. The addition of genetic counselors to the clinical team enables patients to receive specialized advice in a supportive environment dedicated to ALS care. Moreover, predictive test counseling could also be conducted through ALS clinics, rather than patients seeking advice from counselors who have no experience with ALS. In this way, decision making shared with carers and health professionals remains the cornerstone of effective ALS care. Patient-centered decision making will continue to be enacted through the processes and activities of specialized MDCs as new discoveries into the cause and treatment of ALS are made, allowing patient and families to negotiate increasingly complex and complicated life decisions [79].

Financial \& competing interests disclosure

A Crook was supported by the MNDRIA Graham Lang Memorial MND Research grant. The authors have no other relevant affiliations or financial involvement with any organization or entity with a financial interest in or financial conflict with the subject matter or materials discussed in the manuscript apart from those disclosed.

No writing assistance was utilized in the production of this manuscript.

\section{Open access}

This work is licensed under the Attribution-NonCommercial-NoDerivatives 4.0 Unported License. To view a copy of this license, visit http://creativecommons.org/licenses/by-nc-nd/4.0/

\section{References}

Papers of special note have been highlighted as: $\bullet \bullet$ of considerable interest

1. Miller RG, Jackson CE, Kasarskis EJ et al. Practice parameter update: the care of the patient with amyotrophic lateral sclerosis: multidisciplinary care, symptom management and cognitive/behavioral impairment (an evidence-based review): report of the Quality Standards Subcommittee of the American Academy of Neurology. Neurology 73(15), 1227-1233 (2009).

2. O'Brien M, Whitehead B, Jack B, Mitchell JD. Multidisciplinary team working in motor neuron disease: patient and family carer views. Br. J. Neurosci. Nurs. 7(4), 580-585 (2011).

3. Scholl I, Zill JM, Harter M, Dirmaier J. An integrative model of patient-centeredness - a systematic review and concept analysis. PLoS ONE 9(9), e107828 (2014).

4. Castro EM, Van Regenmortel T, Vanhaecht K, Sermeus W, Van Hecke A. Patient empowerment, patient participation and patient-centeredness in hospital care: a concept analysis based on a literature review. Patient Educ. Couns. 99(12), 1923-1939 (2016).

5. Collins A. Measuring what really matters. Toward a coherent measurement system to support person-centered care. The Health Foundation, London, UK (2014). www.health.org.uk/sites/health/files/MeasuringWhatReallyMatters.pdf

6. Makoul G, Clayman ML. An integrative model of shared decision making in medical encounters. Patient Educ. Couns. 60(3), 301-312 (2006).

7. Sandman L, Munthe C. Shared decision making, paternalism and patient choice. Health Care Anal. 18(1), 60-84 (2010).

8. Barry MJ, Edgman-Levitan S. Shared decision making - pinnacle of patient-centered care. N. Engl. J. Med. 366(9), 780-781 (2012).

9. Deber RB, Kraetschmer N, Urowitz S, Sharpe N. Do people want to be autonomous patients? Preferred roles in treatment decision-making in several patient populations. Health Expect. 10(3), 248-258 (2007). 
10. Degner LF, Sloan JA. Decision making during serious illness: what role do patients really want to play? J. Clin. Epidemiol. 45(9), 941-950 (1992).

11. Hamann J, Bieber C, Elwyn G et al. How do patients from Eastern and Western Germany compare with regard to their preferences for shared decision making? Eur. J. Public Health 22(4), 469-473 (2012).

12. Hogden A, Greenfield D, Nugus P, Kiernan MC. What influences patient decision-making in amyotrophic lateral sclerosis multidisciplinary care? A study of patient perspectives. Patient Prefer. Adherence 6, 829-838 (2012).

13. Hogden A, Greenfield D, Nugus P, Kiernan MC. Development of a model to guide decision making in amyotrophic lateral sclerosis multidisciplinary care. Health Expect. 18(5), 1769-1782 (2015).

14. Chewning B, Bylund CL, Shah B, Arora NK, Gueguen JA, Makoul G. Patient preferences for shared decisions: a systematic review. Patient Educ. Couns. 86(1), 9-18 (2012).

15. Rooney J, Byrne $\mathrm{S}$, Heverin $\mathrm{M}$ et al. A multidisciplinary clinic approach improves survival in ALS: a comparative study of ALS in Ireland and Northern Ireland. J. Neurol. Neurosurg. Psychiatry 86(5), 496-501 (2015).

16. Ng L, Khan F, Mathers S. Multidisciplinary care for adults with amyotrophic lateral sclerosis or motor neuron disease. Cochrane Database Syst. Rev. 7(4), CD007425 (2009).

17. Riemenschneider KA, Forshew DA, Miller RG. Multidisciplinary clinics: optimizing treatment for patients with amyotrophic lateral sclerosis. Neurodegen. Dis. Manage. 3(2), 157-167 (2013).

18. Dharmadasa T, Matamala JM, Kiernan MC. Treatment approaches in motor neuron disease. Curr. Opin. Neurol. 29(5), 581-591 (2016).

19. Hardiman O. Multidisciplinary care in motor neuron disease. In: The Motor neuron Disease Handbook. Kiernan MC (Ed.). MJA Books, Sydney, Australia, 164-174 (2007).

20. Hogden A, Foley G, Henderson RD, James N, Aoun SM. Amyotrophic lateral sclerosis: improving care with a multidisciplinary approach. J. Multidiscip. Healthc. 10, 205-215 (2017).

-• Considers amyotrophic lateral sclerosis (ALS) multidisciplinary care from a patient-centered perspective, rather than simply a symptom management approach.

21. Paganoni S, Karam C, Joyce N, Bedlack R, Carter GT. Comprehensive rehabilitative care across the spectrum of amyotrophic lateral sclerosis. NeuroRehabilitation 37(1), 53-68 (2015).

22. NICE Guidance for Motor neuron Disease. www.nice.org.uk/guidance/ng 42

23. Andersen PM, Abrahams S, Borasio GD et al. EFNS guidelines on the clinical management of amyotrophic lateral sclerosis (MALS) revised report of an EFNS task force. Eur. J. Neurol. 19(3), 360-375 (2012).

24. Bede P, Oliver D, Stodart J et al. Palliative care in amyotrophic lateral sclerosis: a review of current international guidelines and initiatives. BMJ Support Palliat. Care 1(3), 343-348 (2011).

25. Hardiman O, Traynor BJ, Corr B, Frost E. Models of care for motor neuron disease: setting standards. Amyotroph. Lateral Scler. Other Motor Neuron Disord. 3(4), 182-185 (2002).

26. Stephens HE, Felgoise S, Young J, Simmons Z. Multidisciplinary ALS clinics in the USA: a comparison of those who attend and those who do not. Amyotroph. Lateral Scler. Frontotemporal Degener. 16(3-4), 196-201 (2015).

27. Corr B, Frost E, Traynor BJ, Hardiman O. Service provision for patients with ALS/MND: a cost-effective multidisciplinary approach. $J$. Neurol. Sci. 160(Suppl. 1), S141-S145 (1998).

28. Henderson RD, Hutchinson N, Douglas JA, Douglas C. Telehealth for motor neuron disease. Med. J. Aust. 201(1), 31 (2014).

29. Lillo P, Savage S, Mioshi E, Kiernan MC, Hodges JR. Amyotrophic lateral sclerosis and frontotemporal dementia: a behavioural and cognitive continuum. Amyotroph. Lateral Scler. 13(1), 102-109 (2012).

30. Lillo P, Mioshi E, Zoing MC, Kiernan MC, Hodges JR. How common are behavioural changes in amyotrophic lateral sclerosis? Amyotroph. Lateral Scler. 12(1), 45-51 (2011).

31. Chio A, Battistini S, Calvo A et al. Genetic counseling in ALS: facts, uncertainties and clinical suggestions. J. Neurol. Neurosurg. Psychiatry 85(5), 478-485 (2014).

32. Mayadev AS, Weiss MD, Distad BJ, Krivickas LS, Carter GT. The amyotrophic lateral sclerosis center: a model of multidisciplinary management. Phys. Med. Rehabil. Clin. N. Am. 19(3), 619-631, xi (2008).

33. Guell MR, Anton A, Rojas-Garcia R, Puy C, Pradas J, En Representacion De Todo El Grupo I. Comprehensive care of amyotrophic lateral sclerosis patients: a care model. Arch. Bronconeumol. 49(12), 529-533 (2013).

34. Economic analysis of motor neuron disease in Australia. www.mndaust.asn.au/Influencing-policy/Economic-analysis-of-MND-(1).aspx

35. Lopez-Bastida J, Perestelo-Perez L, Monton-Alvarez F, Serrano-Aguilar P, Alfonso-Sanchez JL. Social economic costs and health-related quality of life in patients with amyotrophic lateral sclerosis in Spain. Amyotroph. Lateral Scler. 10(4), 237-243 (2009).

36. Aoun SM, Deas K, Kristjanson LJ, Kissane DW. Identifying and addressing the support needs of family caregivers of people with motor neuron disease using the Carer Support Needs Assessment Tool. Palliat. Support Care 15(1), 32-43 (2016). 
37. Larsson BJ, Frojd C, Nordin K, Nygren I. Relatives of patients with amyotrophic lateral sclerosis: their experience of care and support. Palliat. Support Care 13(6), 1569-1577 (2015).

38. Creemers H, De Moree S, Veldink JH, Nollet F, Van Den Berg LH, Beelen A. Factors related to caregiver strain in ALS: a longitudinal study. J. Neurol. Neurosurg. Psychiatry 87(7), 775-781 (2016).

-. This 12-month study uncovers some of the complexities of caregiving for people living with ALS, from patient and carer characteristics. The paper identifies the multidisciplinary clinic as a potential source of support for reducing caregiver strain.

39. Baxter S, Mcdermott CJ. Decision-making and referral processes for patients with motor neuron disease: a qualitative study of GP experiences and evaluation of a new decision-support tool. BMC Health Serv. Res. 17(1), 339 (2017).

40. Gysels M, Shipman C, Higginson IJ. "I will do it if it will help others:" motivations among patients taking part in qualitative studies in palliative care. J. Pain Symptom Manage. 35(4), 347-355 (2008).

41. Gibson SB, Figueroa KP, Bromberg MB, Pulst SM, Cannon-Albright L. Familial clustering of ALS in a population-based resource. Neurol. 82(1), 17-22 (2014).

42. Cady J, Allred P, Bali T et al. Amyotrophic lateral sclerosis onset is influenced by the burden of rare variants in known amyotrophic lateral sclerosis genes. Ann. Neurol. 77(1), 100-113 (2015).

43. Po K, Leslie FV, Gracia N et al. Heritability in frontotemporal dementia: more missing pieces? J. Neurol. 261(11), $2170-2177$ (2014).

44. McCann EP, Williams KL, Fifita JA et al. The genotype-phenotype landscape of familial amyotrophic lateral sclerosis in Australia. Clin. Genet. 92(3), 259-266 (2017).

45. Majounie E, Renton AE, Mok K et al. Frequency of the C9orf72 hexanucleotide repeat expansion in patients with amyotrophic lateral sclerosis and frontotemporal dementia: a cross-sectional study. Lancet Neurol. 11(4), 323-330 (2012).

46. Eisen A, Mezei MM, Stewart HG, Fabros M, Gibson G, Andersen PM. SOD1 gene mutations in ALS patients from British Columbia, Canada: clinical features, neurophysiology and ethical issues in management. Amyotroph Lateral Scler. 9(2), 108-119 (2008).

47. Jiang J, Zhu Q, Gendron TF et al. Gain of toxicity from ALS/FTD-linked repeat expansions in C9ORF72 is alleviated by antisense oligonucleotides targeting GGGGCC-containing RNAs. Neuron 90(3), 535-550 (2016).

48. Miller TM, Pestronk A, David W et al. An antisense oligonucleotide against SOD1 delivered intrathecally for patients with SOD1 familial amyotrophic lateral sclerosis: a Phase I, randomized, first-in-man study. Lancet Neurol. 12(5), 435-442 (2013).

49. Vajda A, Mclaughlin RL, Heverin M et al. Genetic testing in ALS: a survey of current practices. Neurol. 88(10), 991-999 (2017).

-• Results from a survey of 167 ALS clinicians from 21 different countries on their attitudes and practices in relation to genetic testing for ALS genes. There is a lack of consensus among clinicians on this, as well as a standard definition of familial versus sporadic ALS. This paper highlights the need for evidence-based consensus guidelines on genetic testing for ALS.

50. Elwyn G, Gray J, Clarke A. Shared decision making and nondirectiveness in genetic counseling. J. Med. Genet. 37(2), 135-138 (2000).

51. Human Genetics Society of Australasia. Guideline: process of genetic counseling. www.hgsa.org.au/documents/item/13

52. Benatar M, Stanislaw C, Reyes E et al. Presymptomatic ALS genetic counseling and testing: experience and recommendations. Neurol. 86(24), 2295-2302 (2016).

53. Crook A, Williams K, Adams L, Blair I, Rowe DB. Predictive genetic testing for amyotrophic lateral sclerosis and frontotemporal dementia: genetic counseling considerations. Amyotroph. Lateral Scler. Frontotemporal Degener. doi:10.1080/21678421.2017.1332079 (2017) (Epub ahead of print).

-• One of the author's recent literature review articles on predictive genetic testing for at-risk relatives. Results highlight current considerations in the predictive genetic testing process. Gaps in our knowledge and further investigations that are warranted include longer term psychological effects of predictive testing; attitudes of health professionals toward the genetic testing process; the uptake rate of predictive, diagnostic and reproductive genetic testing; and the decision-making process around whether to have genetic testing.

54. Fanos JH, Gronka S, Wuu J, Stanislaw C, Andersen PM, Benatar M. Impact of presymptomatic genetic testing for familial amyotrophic lateral sclerosis. Genet. Med. 13(4), 342-348 (2011).

55. Fanos JH, Gelinas DF, Miller RG. "You have shown me my end": attitudes toward presymptomatic testing for familial amyotrophic lateral sclerosis. Am. J. Med. Genet. A 129A(3), 248-253 (2004).

56. Hartzfeld DE, Siddique N, Victorson D, O’neill S, Kinsley L, Siddique T. Reproductive decision-making among individuals at risk for familial amyotrophic lateral sclerosis. Amyotroph. Lateral Scler. Frontotemporal Degener. 16(1-2), 114-119 (2015).

57. Benatar M, Wuu J. Presymptomatic studies in ALS: rationale, challenges and approach. Neurol. 79(16), 1732-1739 (2012).

58. Riedijk SR, Niermeijer MF, Dooijes D, Tibben A. A decade of genetic counseling in frontotemporal dementia-affected families: few counseling requests and much familial opposition to testing. J. Genet. Couns. 18(4), 350-356 (2009).

59. Skirton H, Goldsmith L, Jackson L, Tibben A. Quality in genetic counseling for presymptomatic testing - clinical guidelines for practice across the range of genetic conditions. Eur. J. Hum. Genet. 21(3), 256-260 (2013).

60. Macleod R, Tibben A, Frontali M et al. Recommendations for the predictive genetic test in Huntington's disease. Clin. Genet. 83(3), 221-231 (2013). 
61. Sorbi S, Hort J, Erkinjuntti T et al. EFNS-ENS guidelines on the diagnosis and management of disorders associated with dementia. Eur. J. Neurol. 19(9), 1159-1179 (2012).

62. Goldman JS, Farmer JM, Van Deerlin VM, Wilhelmsen KC, Miller BL, Grossman M. Frontotemporal dementia: genetics and genetic counseling dilemmas. Neurologist 10(5), 227-234 (2004).

63. Van Blitterswijk M, Van Es MA, Hennekam EA et al. Evidence for an oligogenic basis of amyotrophic lateral sclerosis. Hum. Mol. Genet. 21(17), 3776-3784 (2012)

64. Molinuevo JL, Pintor L, Peri JM et al. Emotional reactions to predictive testing in Alzheimer's disease and other inherited dementias. Am. J. Alzheimers Dis. Other Demen. 20(4), 233-238 (2005).

65. ALSUntangled. www.alsuntangled.com/index.html

66. PatientsLikeMe. www.patientslikeme.com/

67. Seal RP, Kynaston J, Elwyn G, Smith PE. Using an Option Grid in shared decision making. Pract. Neurol. 14(1), $54-56$ (2014).

68. Hogden A, Greenfield D, Caga J, Cai X. Development of patient decision support tools for motor neuron disease using stakeholder consultation: a study protocol. BMJ Open 6(4), e010532 (2016).

69. Stacey D, Legare F, Col NF et al. Decision aids for people facing health treatment or screening decisions. Cochrane Database Syst. Rev. 10, CD001431 (2014)

70. Anderson CJ. The psychology of doing nothing: forms of decision avoidance result from reason and emotion. Psychol. Bull. 129(1), 139-167 (2003).

71. Rapport F, Iredale R, Jones W et al. Decision aids for familial breast cancer: exploring women's views using focus groups. Health Expect. 9(3), 232-244 (2006).

72. Elwyn G, Kreuwel I, Durand MA et al. How to develop web-based decision support interventions for patients: a process map. Patient Educ. Couns. 82(2), 260-265 (2011).

73. Iredale R, Rapport F, Sivell S et al. Exploring the requirements for a decision aid on familial breast cancer in the UK context: a qualitative study with patients referred to a cancer genetics service. J. Eval. Clin. Pract. 14(1), 110-115 (2008).

74. Albrecht UV. Transparency of health-apps for trust and decision making. J. Med. Internet Res. 15(12), e277 (2013).

75. Arthur KC, Calvo A, Price TR, Geiger JT, Chio A, Traynor BJ. Projected increase in amyotrophic lateral sclerosis from 2015 to 2040. Nat. Commun. 7, 12408 (2016)

76. Bucchia M, Ramirez A, Parente V et al. Therapeutic development in amyotrophic lateral sclerosis. Clin. Ther. 37(3), 668-680 (2015).

77. Van Rheenen W, Shatunov A, Dekker AM et al. Genome-wide association analyses identify new risk variants and the genetic architecture of amyotrophic lateral sclerosis. Nat. Genet. 48(9), 1043-1048 (2016).

78. Wagner KN, Nagaraja H, Allain DC, Quick A, Kolb S, Roggenbuck J. Patients with amyotrophic lateral sclerosis have high interest in and limited access to genetic testing. J. Genet. Couns. doi:10.1007/s10897-016-0034-y (2016) (Epub ahead of print).

-• Survey of ALS patients enrolled in the US Agency for Toxic Substances and Disease Registry. This study concluded that ALS patients perceive benefit from genetic counseling, but have limited access to a genetic counseling service. The researchers concluded that genetic counseling should be offered routinely to all ALS patients and this should be enforced in practice guidelines for genetic testing in ALS. This further supports the need for consensus guidelines for genetic testing and counseling in ALS.

79. Foley G, Hynes, G. Decision-making among patients and their family in ALS care: a review. Amyotroph. Lateral Scler. Frontotemporal Degener. doi:10.1080/21678421.2017.1353099 (2017) (Epub ahead of print). 